\title{
INTEREST RATE SENSITIVITY OF SPANISH COMPANIES. AN EXTENSION OF THE FAMA-FRENCH FIVE-FACTOR MODEL
}

\author{
Francisco JAREÑO - María de la O GONZÁLEZ - Marta TOLENTINO - \\ Sara RODRÍGUEZ
}

(Received: 9 November 2017; revision received: 18 February;

accepted: 26 May 2018)

This paper studies the sensitivity of share prices of Spanish companies included in the IBEX-35 to changes in different explanatory variables, such as market returns, interest rates and factors proposed by Fama and French (1993, 2015) between 2000 and 2016. In addition, for robustness, this paper analyses whether the sensitivity of stock returns is different between two periods: precrisis and recent financial crisis. The results confirm that, in general, all the considered factors are relevant. Furthermore, "market return" and "size" factors show greater explanatory power, together with the "value" factor in the crisis period. Regarding the analysis at sector level, "Oil and Energy", "Basic Materials, Industry and Construction" and "Financial and Real Estate Services" sectors appear to be highly sensitive to changes in the risk factors included in the asset pricing factor model.

Keywords: stock market, stock returns, Fama and French factors

JEL classification indices: G11, G15, O51

Francisco Jareño, (corresponding author). Professor at the Department of Economics and Finance, University of Castilla-La Mancha, Faculty of Economic and Business Sciences, Albacete, Spain. E-mail: Francisco.Jareno@uclm.es

María de la $\boldsymbol{O}$ González, Professor at the Department of Economics and Finance, University of Castilla-La Mancha, Faculty of Economic and Business Sciences, Albacete, Spain

E-mail: Mariao.Gonzalez@uclm.es

Marta Tolentino, Professor at the Department of Economics and Finance, University of Castilla-La Mancha, School of Law and Social Sciences, Ciudad Real, Spain.

E-mail: Marta.Tolentino@uclm.es

Sara Rodríguez, Master in Actuarial and Financial Sciences, University of Alcalá, Faculty of Economic and Business Sciences and Tourism, Madrid, Spain. E-mail: saris_mad@hotmail.com 


\section{INTRODUCTION AND LITERATURE REVIEW}

The aim of this paper is to analyse the sensitivity of Spanish stock business returns listed in the Spanish index IBEX-35 to changes in some explanatory factors, such as Spanish stock market returns, short and long term interest rates, the "size" factor (Small Minus Big, SMB), the "value" factor (High Minus Low, HML), the "profitability" factor (Robust Minus Weak, RMW), and the "investment" factor (Conservative Minus Aggressive, CMA), the latter proposed by Fama and French (1993, 2015).

Furthermore, to check the consistency of the results properly, we propose two robustness tests. The first test estimates the extended Fama-French five-factor model (2015, FF5 for short) by splitting the general sample period (January 2000 - April 2016) into sub-periods: pre-crisis (2000-2008) and the financial crisis (2008-2016) periods. The second robustness test estimates this model by using the short-term (instead of long-term) interest rate as nominal interest rate.

A large number of studies have analysed the sensitivity of stock returns to changes in interest rates. Although the bulk of the researches focused on the financial sector, there are also authors who studied the impact on non-financial institutions (Bartram 2002). In addition, it is important to note that fluctuations in interest rates have a relevant power in explaining the variability of financial stock returns (Jianzhou 2007). Regarding the Spanish stock market, some examples are Jareño (2008); Ferrer et al. (2005) and Ferrando et al. (2017), among others.

With respect to non-financial sectors, Bartram (2002) and Jareño (2008) showed a negative and statistically significant relationship between nominal interest rates and stock returns. This is related to the flow-through capability of companies, because according to Jareño - Navarro (2010), the sensitivity of stock returns to changes in interest rates may be lower in the case of companies that have a greater ability to transfer inflationary changes to prices.

Changes in interest rates do not affect all sectors in a homogeneous way. The divergence may be due to different factors, such as the level of liquidity, the composition of the asset, the level of leverage, the business structure and the flowthrough capability (Jareño 2008; Jareño - Navarro 2010).

The factor asset pricing models can be classified into two branches: firstly, the Stone (1974) two-factor model, in which market return and interest rate are the main explanatory variables of changes in stock returns (Jareño et al. 2016), and secondly, the Fama-French model (1993, 2015), which proposes the three- and five-factor models, where the expected returns are related to risk factors, such as the stock market return minus the risk-free interest rate, and additional factors related to the "size", "value", "profitability" and "investment". In concrete, FF5 
expanded the three-factor model by incorporating two additional factors: "profitability" (RMW) and "investment" (CMA).

This innovative asset pricing factor model is applied in recent researches about investment allocation strategies (Angelidis - Tessaromatis 2017), the analysis of US service sector (Yang et al. 2017), and testing the five-factor model for different stock markets (Harshita et al. 2015; Chia et al. 2016; Guo et al. 2017; Fama - French 2017, among others). It should be noted that there is a shortage of papers analysing the impact of the factors proposed by FF5 on the Spanish stock market, especially at company level. Specifically, the analysis of the Spanish market is only residually collected in an original work by Fama - French (2017), as well as in He et al. (2015) and Huynh (2017), as the Spanish stock market is integrated into a European portfolio. Nevertheless, there would not be any particular study only focused on the Spanish stock market.

The most relevant contributions of this research are the following ones: First, to the best of our knowledge, it is the first study that analyses the sensitivity of the Spanish stock market at company level in the framework of FF5 during the period of 2000-2016. Second, to check the robustness of the results, the full sample period has been divided into two sub-periods: pre-crisis and global financial crisis periods. In this way, depending on the economic cycle, the sensitivity of certain Spanish stock returns to changes in risk factors may vary. Moreover, to do a second robustness test of our results, this paper proposes two variations of the augmented FF5, using alternatively short- and long-term interest rates.

The rest of the paper is presented in the following way: Section 2 includes discussions on data and methodology. Section 3 shows the empirical results of the augmented Fama-French five-factor asset pricing model. Section 4 includes some robustness checks to confirm the reliability of the results. Finally, Section 5 comprises the main conclusions.

\section{DATA AND METHODOLOGY}

\subsection{Data and sample period}

The sample period chosen for the analysis is between January 2000 and April 2016, which consists of a pre-crisis sub-sample (from January 2000 to August 2008) and the financial crisis sub-sample (from September 2008 to April 2016) ${ }^{1}$ periods. The reason for this separation is that we can assume that the effect of

Although the sample period spans from January 2000 to April 2016, some companies were not on the stock exchange for the whole period. 
different factors may depend on the economic cycle (Jareño et al. 2016; Ferrando et al. 2017, among others).

Regarding the data frequency, it considers a monthly average of each business return (196 observations total). This study includes the returns of IBEX-35 companies as a dependent variable and the stock market return, long term interest rates, ${ }^{2}$ and the factors proposed by Fama and French, such as "size" factor (SMB), "value" factor (HML), "profitability" factor (RMW), and "investment" factor (CMA), as independent or explanatory variables. In actual, this paper uses the original FF5. According to Angelidis - Tessaromatis (2017), among others, FF5 have broad support and acceptance in the academic community and are the basis for country and global smart beta portfolio strategies used by both institutional and retail investors. Furthermore, while the previous literature usually studies the effect of national variables on the national stock market, Sevillano Jareño (2018) study to what extent the genuine European Fama-French factors impact the Spanish stock market at company level. Therefore, to some extent, this paper finally studies whether there is an interconnection between international stock markets.

Table 1 shows the companies analysed according to the sectors. We used the composition of the IBEX-35 on April 3, 2016, to study the temporal evolution of these companies based on different factors. Thus, the static analysis of the companies included in the Spanish IBEX-35 index (at that particular point in time) may imply lack of data for certain companies in specific sub-periods, due to the possible entry and exit of some selected companies during the sample period. ${ }^{3}$

The Spanish stock business and stock market returns (the Spanish IBEX-35 index) are extracted from the website of Invertia. Then the logarithmic returns are obtained. ${ }^{4}$ Regarding the main descriptive statistics of companies' returns listed in the IBEX-35, there are relevant differences between the companies. ${ }^{5}$ AENA is the company with the highest mean return followed by other companies, such as Amadeus, Grifols, IAG, Inditex and Red Eléctrica Corporación. On the other hand, Bankia is the company with a lower mean return along the sample, accompained with Arcelomittal, CaixaBank and Sacyr. With regard to the median, AENA, International Consolidat Airlines Group, Grifols, Enagas and Inditex are the companies with the highest median return, whereas CaixaBank and Bankia have a much lower median than the rest. Bankia has the highest risk, jointly with

\footnotetext{
Short-term interest rates are used for robustness.

Some previous studies, such as Sevillano - Jareño (2018), take similar decisions.

Closing prices are adjusted by dividends and splits.

The descriptive statistics and unit root tests are available upon request.
} 
Table 1. Companies and sectors analysed

\begin{tabular}{|c|c|}
\hline & Code \\
\hline \multicolumn{2}{|l|}{ Sector 1: Oil and Energy } \\
\hline Repsol, S.A. & R30 \\
\hline Enagás, S.A. & R14 \\
\hline Endesa, S.A. & R13 \\
\hline Iberdrola, S.A. & $\mathrm{R} 21$ \\
\hline Gas Natural, S.A. & R18 \\
\hline Red Eléctrica Corporación (REE), S.A. & R29 \\
\hline \multicolumn{2}{|c|}{ Sector 2: Basic Materials, Industry and Construction } \\
\hline Acerinox, S.A. & R3 \\
\hline Arcelomittal, S.A. & R26 \\
\hline Gamesa Corporación Tecnológica, S.A. & R17 \\
\hline Acciona, S.A. & R2 \\
\hline Actividades de Construcción y Servicios, S.A. & R4 \\
\hline Ferrovial, S.A. & R16 \\
\hline Fomento, Construcción y Contratas, S.A. & R15 \\
\hline Sacyr, S.A. & R32 \\
\hline Obrascon Huarte Lain, S.A. & R27 \\
\hline Técnicas Reunidas, S.A. & R35 \\
\hline \multicolumn{2}{|l|}{ Sector 3: Consumer Goods } \\
\hline Grifols, S.A. & R19 \\
\hline \multicolumn{2}{|l|}{ Sector 4: Consumer Services } \\
\hline Dia, distribuidora int. de alimientación, S.A. & R12 \\
\hline Mediaset España Comunicación, S.A. & R34 \\
\hline Industria de Diseño Textil, S.A. "Inditex" & $\mathrm{R} 22$ \\
\hline International Consolidat Airlines Group & $\mathrm{R} 20$ \\
\hline Aena, S.A. & R5 \\
\hline Abertis Infraestructuras, S.A. & $\mathrm{R} 1$ \\
\hline \multicolumn{2}{|l|}{ Sector 5: Financial and Real Estate Services } \\
\hline Banco Bilbao Vizcaya Argentaria, S.A. & R28 \\
\hline Banco Sabadell, S.A. & R8 \\
\hline Banco Popular Español, S.A. & R7 \\
\hline Banco Santander, S.A. & R31 \\
\hline Bankia, S.A. & R9 \\
\hline Bankinter, S.A. & R10 \\
\hline Caixabank, S.A. & R11 \\
\hline Mapfre, S.A. & R24 \\
\hline Merlin Properties, SOCIMI, S.A. & R25 \\
\hline \multicolumn{2}{|l|}{ Sector 6: Technology and Telecommunications } \\
\hline Telefónica, S.A. & R33 \\
\hline Amadeus IT Holding, S.A. & R6 \\
\hline Indra Sistemas, S.A. & $\mathrm{R} 23$ \\
\hline
\end{tabular}

Source: Own preparation based on the Bolsas y Mercados Españoles (BME) website. 
Arcelomittal and Sacyr. Furthermore, nearly all the companies present negative asymmetry and there is not a considerable excess of kurtosis.

As regards the explanatory variables, data concerning market returns have been extracted from the Bolsa de Madrid website, through the returns of the IBEX-35 Spanish market index. In the case of stock business returns, the logarithmic returns were calculated. Continuing with the bulk of the previous literature, the impact of the interest rate has been analysed. ${ }^{6}$ More specifically, 10-year (longterm, IR) and 3-month (short-term, RF) nominal interest rates corresponding to the public debt provided by the official Banco de España website are used in the paper. $^{7}$

According to Ferrer et al. (2010) and Akhtaruzzaman et al. (2014), stock business returns may be more sensitive to changes in long-term interest rates than short-term rates. Long-term interest rates incorporate market expectations about the economic cycle, long-term government bonds can be considered as closer maturity substitutes to stocks, and long term rates are more stable. Therefore, the extended FF5 model is estimated by using long-term interest rates, in particular, 10 -year nominal interest rates. Besides, for robustness, the model is also estimated including 3-month interest rates.

The rest of the explanatory variables are extracted from the Kenneth R. French website, ${ }^{8}$ such as SMB, HML, RMW, and CMA.

The main descriptive statistics of the explanatory variables show a positive mean for all variables, except the stock market return. The HML is the most important factor, whereas the market return shows a much lower value than the rest. In addition, most variables have a median very close to their mean value. With regard to the standard deviation, the Fama and French explanatory factors show more dispersion than the rest of the variables included in the analysis. Finally, half of the values are scattered to the right of the distribution and half of the values are distributed to the left.

Three tests are implemented to study the stationarity of the time series: two unit root tests, such as Augmented Dickey-Fuller (ADF) and Phillips-Perron (P-P) and one stationarity test that is Kwiatkowski-Phillips-Schmidt-Shin (KPSS). ${ }^{9}$ Almost all the variables included in the analysis are stationary that is the mean and the median remain constant during the sample period. Only the explanatory

6 After studying the effect of 1-year and 10-year nominal interest rates, the results showed greater effect of the second, which is supported by the inclusion of this variable in most of the works analysed in the literature review (Ferrando et al. 2015).

https://www.bde.es/bde/es/areas/mercadeuda/

http://mba.tuck.dartmouth.edu/pages/faculty/ken.french/data_library.html

These results are available upon request. 
variables, such as short and long-term interest rates, CMA and HML, which had a unit root, have to be transformed into first differences.

Finally, to avoid collinearity between explanatory factors, the correlation matrix was studied. ${ }^{10}$ There is a statistically significant correlation between stock market returns and SMB. The rest of the correlations are not statistically significant. So it is not necessary to orthogonalize risk factors included in the augmented FF5 model. Moreover, it is usually advised to avoid the orthogonalization process to keep the genuine risk factors.

\subsection{Methodology}

We propose an extension of FF5 that explains the companies' returns according to the following explanatory variables: market returns, nominal interest rates, "size" factor - SMB, "value" factor - HML, "profitability" factor - RMW, and "investment" factor - CMA. Thus, the extended FF5 model that includes longterm interest rates is represented as follows:

$$
R_{j t}=\alpha_{j}+\beta_{j} \cdot M R_{t}+\mu_{j} \cdot \Delta I R_{t}+\gamma_{f} \cdot S M B_{t}+\tau_{f} \cdot \Delta H M L_{t}+\varphi_{f} \cdot R M V_{t}+\delta_{f} \cdot \Delta C M A_{t}+\varepsilon_{j t}
$$

where $\mathrm{R}_{j t}$ is the monthly return of company $j, \alpha_{j}$ is the independent term, $\beta_{j}$ shows the market sensitivity of company $j$ listed in the Spanish index IBEX-35, $M R_{t}$ is the monthly market return, $\mu_{j}$ shows the sensitivity of company $j$ to unexpected changes in long-term nominal interest rates, $\Delta I R_{t}$ is the non-expected change in the long-term nominal interest rate, $\gamma_{f}$ shows the sensitivity of company $j$ to changes in the "size" factor, $S M B_{t}$ shows the monthly "size" factor return, $\tau_{f}$ shows the sensitivity of company $j$ to changes in the "value" factor, $H M L_{t}$ is the monthly "value" factor return, $\varphi_{f}$ shows the sensitivity of company $j$ to changes in the "profitability" factor, $R M V_{t}$ shows the monthly "profitability" factor return, $\delta_{f}$ shows the sensitivity of company $j$ to changes in the "investment" factor, $C M A_{t}$ shows the monthly "investment" factor return and, finally, $\varepsilon_{j t}$ is a random disturbance.

The estimation of the extended FF5 has been done through a system of thirtyfive equations (as many as dependent variables are included in the analysis) following the methodology of the Seemingly Unrelated Regression (SUR) models. Several authors used this methodology because it allows to avoid the distortions in the estimates due to the presence of heteroscedasticity and simultaneous correlation between the error terms (e.g. Jareño 2008). 


\section{MAIN RESULTS}

The empirical analysis (Sections 3 and 4) is multipurpose. First, it carries out a study considering the whole sample period (Jan 2000 - Apr 2016) and the longterm interest rates as additional explanatory factor. Then, for robustness, estimations are also carried out for two sub-periods: pre-crisis (Jan 2000 - Aug 2008) and recent financial crisis (Sept 2008 - Apr 2016) sub-periods. ${ }^{11}$ Moreover, this paper also estimates the proposed model with the short-term interest rates instead of the long-term ones. This allows us to corroborate the consistency of the results obtained.

\subsection{Estimates of the extended Fama and French five-factor model (2015)}

The results of the extended FF5 model for the full period and using long-term interest rates are shown in Table 2. It allows to study the relationships between the IBEX-35 companies' returns and the explanatory risk factors.

All the companies, except for R25 (Merlin Properties), have a positive and statistically significant sensitivity to changes in the stock market returns, so a change in this risk factor would imply a change in the same direction in these companies' returns. The value of the coefficients is less than one in all cases, except for R9 (Bankia), R26 (Mittal Steel Company) and R32 (Sacyr), so if the stock market return is positive, these companies would outperform the market, and vice versa. Furthermore, the companies, R11 (Caixabank), R17 (Gamesa), R27 (OHL), R28 (BBVA), R31 (Banco Santander), R34 (Mediaset España) and R35 (Técnicas Reunidas) present coefficients close to one, so their behaviour is close to the Spanish stock market.

The sensitivity of the returns to changes in the long-term interest rate is statistically significant for about $29 \%$ of the companies: R8 (Banco Sabadell), R11 (Caixa Bank), R12 (Día), R17 (Gamesa Corporación Tecnológica), R22 (Inditex), R26 (Mittal Steel Company), R27 (OHL), R30 (Repsol), R31 (Banco Santander) and R35 (Técnicas Reunidas). All companies have positive sign (future expectations) except for Banco Sabadell. Moreover, Día, Mittal Steel Company and Técnicas Reunidas are most sensitive to the changes in long-term interest rates.

The "size" (SMB) factor is statistically significant for almost $72 \%$ of the companies analysed. In addition, it is positive in all cases, that is, the larger the company size, the greater its returns. For the companies, such as Gamesa, Arce-

11 We have split the whole sample into two sub-samples considering the fall of Lehman Brothers Holdings. 
Table 2. Estimates for the whole sample and long-term interest rates

\begin{tabular}{|c|c|c|c|c|c|c|c|}
\hline Companies & MR & $\Delta \mathbf{I R}$ & SMB & $\Delta$ HML & RMW & $\triangle \mathrm{CMA}$ & Adj. $R^{2}$ \\
\hline R1 & $0.3769^{* * * *}$ & -0.5619 & $0.0034^{* *}$ & 0.0009 & \begin{tabular}{|l|}
0.0003 \\
\end{tabular} & 0.0023 & 0.1863 \\
\hline R2 & $0.6342^{* * *}$ & 0.3634 & $0.0086^{* * *}$ & -0.0004 & 0.0008 & 0.0022 & 0.2225 \\
\hline R3 & $0.5702^{* * *}$ & 2.1542 & $0.0076^{* * *}$ & 0.0025 & \begin{tabular}{|l|}
0.0002 \\
\end{tabular} & 0.0016 & 0.2535 \\
\hline R4 & $0.4722^{* * *}$ & -1.6684 & $0.0040^{*}$ & 0.0016 & -0.0016 & $0.0047^{* *}$ & 0.2083 \\
\hline R5 & $0.6754^{*}$ & -2.5439 & 0.0145 & 0.0039 & -0.0145 & \begin{tabular}{|l|}
0.0054 \\
\end{tabular} & 0.4864 \\
\hline R6 & $0.2345^{* * *}$ & 1.9282 & 0.0029 & -0.0023 & -0.0038 & \begin{tabular}{|l|}
0.0007 \\
\end{tabular} & -0.0019 \\
\hline R7 & $0.4729^{* * * *}$ & -3.3151 & $0.0060^{* *}$ & $-0.0050^{*}$ & $-0.0136^{* * *}$ & 0.0019 & 0.1769 \\
\hline R8 & $0.5920^{* * *}$ & $-3.5479^{* *}$ & $0.0036^{*}$ & 0.0008 & -0.0005 & $0.0041^{*}$ & 0.3093 \\
\hline R9 & $2.0972^{*}$ & -13.5076 & 0.0323 & 0.0119 & \begin{tabular}{|l|}
0.0474 \\
\end{tabular} & \begin{tabular}{|l|}
0.0131 \\
\end{tabular} & -0.0341 \\
\hline R10 & $0.5528^{* * *}$ & 0.1277 & $0.0068^{* * *}$ & -0.0039 & -0.0041 & $0.0048^{*}$ & 0.2047 \\
\hline R11 & $0.8037^{* * *}$ & $2.8251^{*}$ & $0.0059^{* *}$ & $-0.0045^{* *}$ & $-0.0100^{* *}$ & -0.0003 & 0.4180 \\
\hline R12 & $0.5784^{* * *}$ & $6.2755^{* * *}$ & -0.0001 & -0.0020 & -0.0082 & -0.0048 & 0.1208 \\
\hline R13 & $0.4746^{* * *}$ & 1.2279 & $0.0043^{*}$ & $-0.0065^{* * *}$ & $-0.0083^{* *}$ & $0.0081^{* * *}$ & 0.1709 \\
\hline R14 & $0.4106^{* * *}$ & -0.3225 & $0.0030^{* *}$ & -0.0010 & \begin{tabular}{|l|}
0.0000 \\
\end{tabular} & 0.0007 & 0.2346 \\
\hline R15 & $0.5945^{* * *}$ & -1.7339 & 0.0023 & -0.0026 & -0.0005 & $0.0094^{* * *}$ & 0.1982 \\
\hline R16 & $0.6815^{* * *}$ & 2.5280 & $0.0072^{* * *}$ & -0.0003 & $0.0076^{* *}$ & 0.0036 & 0.2572 \\
\hline R17 & $0.9507^{* * *}$ & $4.2456^{*}$ & $0.0158^{* * *}$ & -0.0032 & -0.0050 & \begin{tabular}{|l|}
0.0051 \\
\end{tabular} & 0.3167 \\
\hline R18 & $0.4409^{* * *}$ & 0.4534 & 0.0018 & $-0.0054^{* * * *}$ & -0.0045 & $0.0062^{* * *}$ & 0.1747 \\
\hline R19 & $0.5723^{* * *}$ & 2.4639 & $0.0091^{* * *}$ & -0.0023 & \begin{tabular}{|l|}
0.0037 \\
\end{tabular} & -0.0012 & 0.1640 \\
\hline R20 & $0.6118^{* * * *}$ & 0.8806 & 0.0074 & $-0.0062^{*}$ & -0.0064 & -0.0068 & 0.1570 \\
\hline R21 & $0.4401^{* * *}$ & -0.3718 & $0.0028^{*}$ & -0.0013 & -0.0010 & $0.0046^{* * *}$ & 0.2335 \\
\hline R22 & $0.5413^{* * *}$ & $2.3490^{*}$ & $0.0043^{* *}$ & 0.0018 & $0.0086^{* * *}$ & 0.0008 & 0.2112 \\
\hline R23 & $0.6459^{* * *}$ & 0.9725 & $0.0082^{* * *}$ & -0.0014 & -0.0021 & \begin{tabular}{|l|}
0.0029 \\
\end{tabular} & 0.3155 \\
\hline R24 & $0.5258^{* * *}$ & 0.0647 & $0.0069^{* * *}$ & $-0.0038^{*}$ & $-0.0085^{* * * *}$ & $0.0085^{* * *}$ & 0.2980 \\
\hline R25 & 0.4985 & -0.2662 & 0.0027 & 0.0043 & \begin{tabular}{|l|}
0.0012 \\
\end{tabular} & 0.0014 & 0.0184 \\
\hline R26 & $1.1454^{* * *}$ & $10.5384^{* * *}$ & $0.0180^{* * *}$ & -0.0028 & -0.0096 & -0.0025 & 0.3586 \\
\hline R27 & $0.8786^{* * *}$ & $3.8276^{*}$ & $0.0134^{* * *}$ & -0.0041 & -0.0039 & $0.0087^{* * *}$ & 0.2686 \\
\hline R28 & $0.8566^{* * *}$ & 1.1070 & $0.0042^{* *}$ & -0.0026 & $-0.0076^{* * *}$ & $0.0045^{* *}$ & 0.5205 \\
\hline R29 & $0.3095^{* * *}$ & -0.5205 & 0.0022 & 0.0002 & -0.0015 & $0.0056^{* * *}$ & 0.1165 \\
\hline R30 & $0.5985^{* * *}$ & $2.4454^{*}$ & $0.0033^{*}$ & -0.0002 & -0.0006 & 0.0008 & 0.2500 \\
\hline R31 & $0.8679^{* * *}$ & $2.4467^{*}$ & $0.0050^{* * *}$ & -0.0017 & $-0.0062^{* *}$ & $0.0052^{* * *}$ & 0.4974 \\
\hline R32 & $1.0758^{* * *}$ & 1.6105 & $0.0101^{* * *}$ & -0.0042 & \begin{tabular}{|l|}
-0.0058 \\
\end{tabular} & \begin{tabular}{|l}
$0.0061^{*}$ \\
\end{tabular} & 0.3035 \\
\hline R33 & $0.6864^{* * *}$ & 0.2487 & 0.0021 & -0.0015 & -0.0011 & 0.0008 & 0.3894 \\
\hline R34 & $0.7935^{* * *}$ & 2.0856 & $0.0063^{*}$ & -0.0006 & $-0.0091^{*}$ & -0.0010 & 0.3225 \\
\hline R35 & $0.9610^{* * *}$ & $7.8065^{* * *}$ & $0.0163^{* * *}$ & 0.0002 & 0.0013 & -0.0008 & 0.3733 \\
\hline
\end{tabular}

Notes: MR: Spanish stock market return, IR: (long-term) interest rate, SMB: size factor, HML: value factor, RMW: profitability factor, CMA: investment factor.

${ }^{*} p<0.10,{ }^{* *} p<0.05,{ }^{* * *} p<0.01$

Source: Own preparation from Eviews results. 
lomittal, OHL, Sacyr and Técnicas Reunidas, the coefficients are higher and, therefore, these companies are more sensitive to changes in the SMB variable. In contrast, the less sensitive companies are Abertis, Banco Sabadell and Iberdrola. This variable is not statistically significant for R5 (Aena), R6 (Amadeus), R9 (Bankia), R12 (Dia), R18 (Gas Natural Fenosa), R20 (International Consolidat Airlines Group), R25 (Merlin Properties), R29 (Red Eléctrica Corporación) and R33 (Telefónica).

The "value" (HML) factor has a statistically significant effect on R7 (Banco Popular), R11 (Caixa Bank), R13 (Endesa), R18 (Gas Natural Fenosa), R20 (International Consolidat Airlines Group) and R24 (Mapfre). In addition, it has negative sign, which means that the companies may obtain lower returns when their growth opportunities are greater.

The "profitability" (RMW) factor is statistically significant for about $26 \%$ of the companies, such as R7 (Banco Popular), R11 (Caixabank), R13 (Endesa), R16 (Ferrovial), R22 (Inditex), R24 (Mapfre), R28 (BBVA), R31 (Banco Santander) and R34 (Mediaset España). In addition, this sensitivity is negative for all of them, except for Ferrovial and Inditex, which is positive, although with a very small associated coefficient.

The "investment" (CMA) explanatory factor is statistically significant and shows a positive sign for about $37 \%$ of the companies: R4 (Actividades de Construcción y Servicios), R8 (Banco Sabadell), R10 (Bankinter), R13 (Endesa), R15 (Fomento, Construcción y Contratas), R18 (Gas Natural Fenosa), R21 (Iberdrola), R24 (Mapfre), R27 (Obrascon Huarte Lain), R28 (BBVA), R29 (Red Eléctrica Corporación), R31 (Banco Santander) and R32 (Sacyr). Therefore, the return of these companies would be greater when having the greater CMA factor. The most sensitive companies are Endesa, Fomento, Construcción y Contratas, Mapfre and OHL. On the contrary, those that are less sensitive are Actividades de Construcción y Servicios, Banco Sabadell, Bankinter, Iberdrola and BBVA. In this proof, the explanatory power is quite different between companies. The adjusted $\mathrm{R}^{2}$ is about $25 \%$ on average and almost $50 \%$ for R5 (Aena).

\subsection{Analysis at sector level}

Table 3 shows the results at sector level to remark possible and relevant differences among them.

First, the weight of each sector in proportion to the number of companies is the following: more than $28 \%(10 / 35)$ for sector 2 , about $26 \%(9 / 35)$ for sector 5 , slightly more than $17 \%(5 / 35)$ for sectors 1 and 4 , about $9 \%(3 / 35)$ for sector 6 , and finally, about $3 \%(1 / 35)$ for sector 3 . 


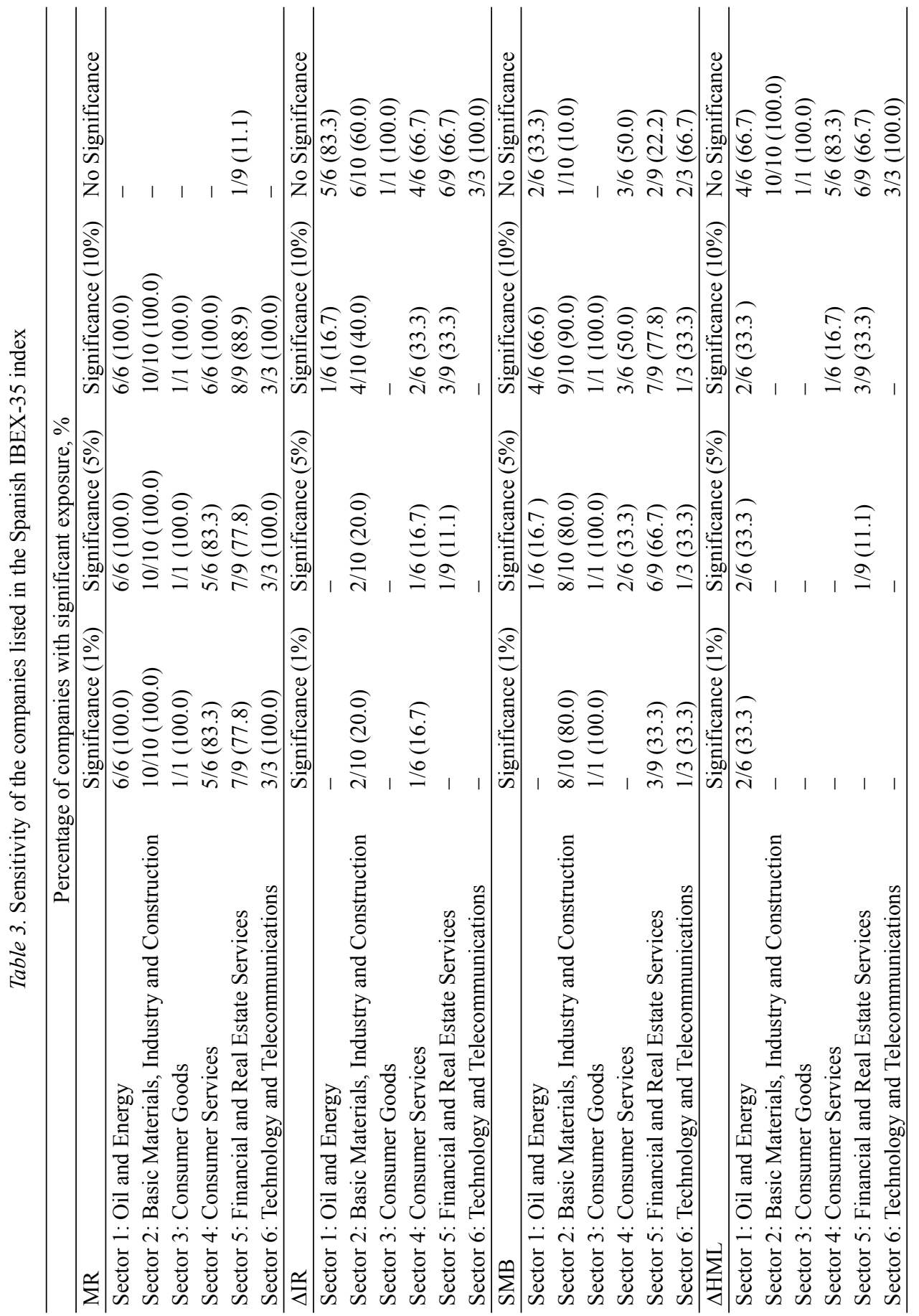




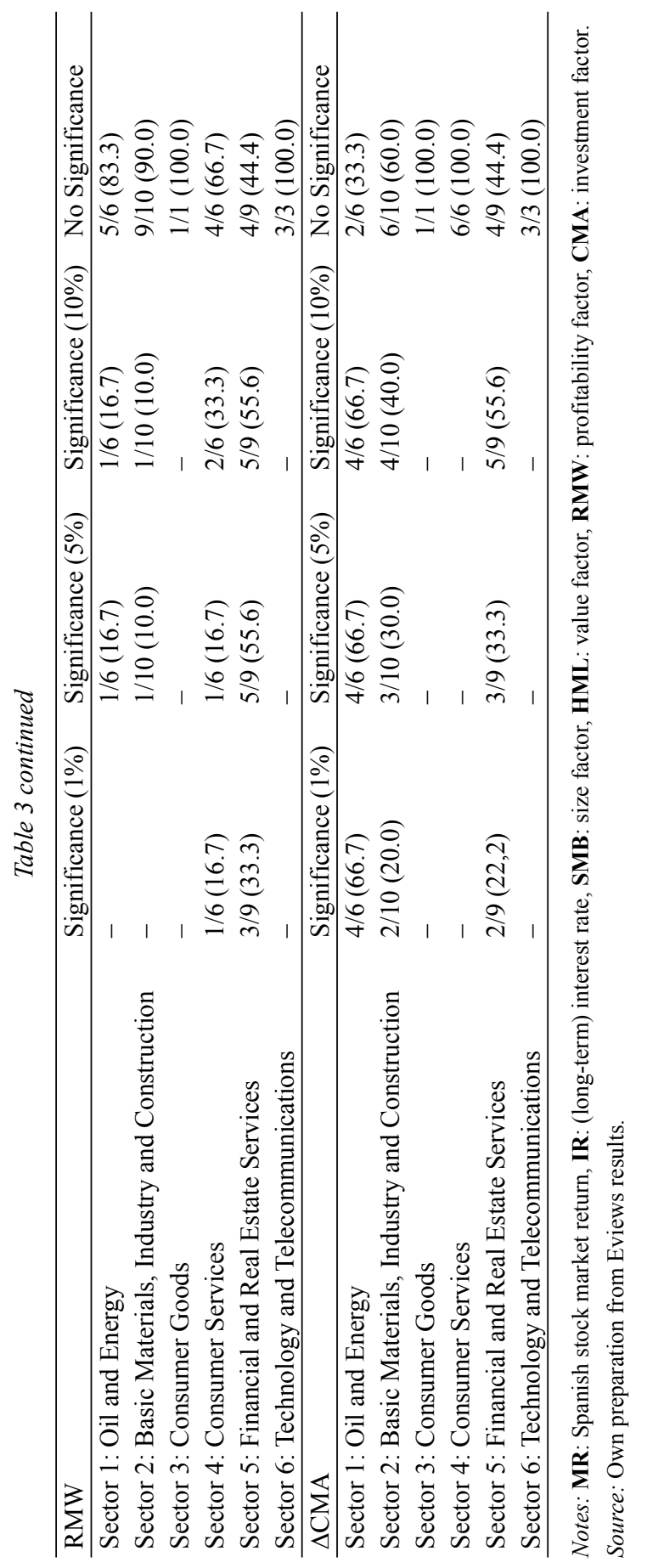


With regard to market returns, all except one of the sectors show a hundred per cent of companies with statistically significant sensitivity, so, stock business returns are mainly affected by the variations in market returns. The exception is sector 5 that exhibits $89 \%$ of companies with statistically significant sensitivity at $10 \%$ level.

As far as changes in interest rates are concerned, sector 2 shows the greatest sensitivity to changes in this risk factor proposed in this research $(40 \%$ of companies). Furthermore, sectors 4 and 5 reach $33.3 \%$ of companies with statistically significant sensitivity to changes in long-term interest rates.

Most companies of all sectors present statistically significant sensitivity to variations in the "size" factor (SMB). Specifically, $100 \%, 90 \%$ and $78 \%$ of companies of the sectors 3,2 and 5, respectively, are highly sensitive to changes in SMB. As regards the "value" factor (HML), it primarily shows statistically significant impact on sectors 1 and 5 (33.3\% of companies).

The "profitability" factor (RMW) exhibits a greater impact than the "value" factor. Sector 5 shows that about $56 \%$ of companies are with statistically significant sensitivity to changes in this risk factor. Besides, sector 4 contains $33 \%$ of companies sensitive to RMW.

The most sensitive sector to changes in the "investment" factor (CMA) is sector 1 with $66.7 \%$ of companies showing statistically significant sensitivity to changes in this risk factor, followed by sector 5 with a $55.6 \%$ of companies and, in third position, sector 2 with $40 \%$ of companies sensitive to the investment factor.

Finally, the mean explanatory power at sector level is between $17 \%$ and $28 \%$. Moreover, sectors 2 and 5 exhibit the highest adjusted $\mathrm{R}^{2}$ values.

\section{ROBUSTNESS CHECKS}

This section includes two tests to check the robustness of the findings of the previously estimated augmented FF5 (Equation 1). First, the FF5 model has been estimated splitting the whole sample into two different sub-periods: pre crisis sub-period and crisis sub-period. Second, the sensitivity of stock business returns to changes in short-term interest rates (proxied by 3-month treasury bill rates) has been estimated. The inclusion of this variable instead of long-term interest rates (10-year government bond yields) in the extended Fama-French specification allows for contrasting the reliability of the results. 


\subsection{Sub-sample analysis}

For robustness, this section studies the effect that the economic crisis may have on the relationship between the individual stock returns of the companies listed in the IBEX-35 index and the explanatory variables included in the extension of FF5 model proposed in this research. For that end, this study breaks the whole sample into two different sub-periods: pre crisis sub-period (January 2000 - August 2008) and recent financial crisis sub-period (September 2008 - April 2016). The division into these two consecutive sub-periods is determined by the beginning of the crisis with the fall of Lehman Brothers in September 2008 (Ferrando et al. 2017). So, recent economic events have been taken into account in this analysis

\subsubsection{Pre-crisis sub-period: Janurary 2000 - August 2008}

This sub-section performs an analysis of the IBEX-35 companies' returns for the first sub-sample, the pre-crisis sub-period. It should be noted that for some companies the analysis could not be carried out since there were no quotations data for these dates or they were not enough to obtain reliable estimates. These companies are Aena, Amadeus, IT Holding, Caixabank, Día, IAG and Merlin. ${ }^{12}$

Table 4 shows the estimates of the factor model proposed in this research including long-term interest rates for this sub-period.

All companies present a statistically significant and positive sensitivity to changes in the stock market return, except for R1 (Abertis) and R7 (Banco Popular). Thus, these results practically coincide with the ones of the full period since the companies that do not offer statistical significance are the same. In this case there is no coefficient greater than one, but five companies with the coefficient value closest to one, such as R17 (Gamesa), R19 (Grifols), R23 (Indra), R33 (Telefónica) and R35 (Técnicas Reunidas), present a behaviour quite similar to the market. In contrast, the companies with a lowest sensitivity are R2 (Acciona), R3 (Acerinox), R4 (Actividades de Construcción y Servicios, ACS), R21 (Iberdrola) and R29 (REE).

With regard to the long-term interest rate, $21.4 \%$ of the companies show statistically significant sensitivity. Specifically, the companies that present a statistically significant and positive sensitivity are R2 (Acciona), R8 (Banco Sabadell),

12 As previously explained, Table 4 does not show results for some specific companies, such as RS5, RS6, RS9, RS11, RS12, RS20 and RS25. The static analysis of the companies included in the Spanish IBEX-35 index (April 3, 2016) indeed implies lack of data for these companies during the pre-crisis sub-period, due to their later entry in the composition of the Spanish stock market index. 
Table 4. Estimates for the pre-crisis sub-sample and long-term interest rates

\begin{tabular}{|c|c|c|c|c|c|c|c|}
\hline Companies & MR & $\Delta \mathbf{I R}$ & SMB & $\Delta$ HML & RMW & $\triangle \mathrm{CMA}$ & Adj. $R^{2}$ \\
\hline R1 & 0.1665 & -0.8664 & 0.0025 & 0.0019 & 0.0038 & 0.0011 & 0.0087 \\
\hline $\mathbf{R 2}$ & $0.3645^{*}$ & $6.0008^{*}$ & $0.0072^{* * *}$ & 0.0011 & 0.0036 & -0.0006 & 0.1587 \\
\hline R3 & $0.3327^{* *}$ & 5.5798 & $0.0080^{* * *}$ & $0.0070^{* *}$ & 0.0024 & -0.0005 & 0.1758 \\
\hline R4 & $0.3626^{*}$ & -2.1382 & 0.0031 & 0.0074 & -0.0003 & 0.0033 & 0.1745 \\
\hline R7 & 0.3347 & -7.5738 & 0.0042 & -0.0043 & -0.0113 & 0.0005 & 0.0489 \\
\hline R8 & $0.4600^{* * *}$ & $8.0538^{* * *}$ & $0.0077^{* * * *}$ & -0.0022 & 0.0041 & 0.0035 & 0.3255 \\
\hline R10 & $0.6536^{* * *}$ & $6.8050^{*}$ & $0.0079^{* * *}$ & 0.0025 & 0.0019 & 0.0021 & 0.3562 \\
\hline R13 & $0.5973^{* * *}$ & 0.1968 & 0.0024 & 0.0033 & -0.0025 & 0.0030 & 0.3432 \\
\hline R14 & $0.5202^{* * *}$ & -3.4537 & 0.0031 & 0.0027 & 0.0056 & -0.0015 & 0.1530 \\
\hline R15 & $0.4814^{* * *}$ & 1.0710 & 0.0018 & $0.0072^{*}$ & 0.0037 & 0.0036 & 0.2544 \\
\hline R16 & $0.5131^{* * *}$ & 1.2054 & $0.0068^{* * *}$ & $0.0063^{*}$ & $0.0093^{* *}$ & -0.0002 & 0.2159 \\
\hline R17 & $0.7826^{* * *}$ & $8.0818^{*}$ & 0.0075 & 0.0043 & 0.0074 & 0.0007 & 0.2586 \\
\hline R18 & $0.4485^{* * *}$ & $-5.8476^{* *}$ & -0.0013 & 0.0017 & 0.0045 & 0.0033 & 0.1617 \\
\hline R19 & $0.8103^{* *}$ & 8.9273 & 0.0123 & 0.0083 & -0.0125 & -0.0004 & 0.1913 \\
\hline R21 & $0.3603^{* * *}$ & -2.0652 & -0.0003 & \begin{tabular}{|l|}
0.0020 \\
\end{tabular} & 0.0050 & $0.0050^{* *}$ & 0.1597 \\
\hline R22 & $0.5834^{* * *}$ & 2.8778 & 0.0048 & -0.0055 & 0.0083 & 0.0024 & 0.1441 \\
\hline $\mathbf{R 2 3}$ & $0.9470^{* * *}$ & -1.4811 & $0.0071^{* * *}$ & \begin{tabular}{|l}
$0.0046^{*}$ \\
\end{tabular} & 0.0000 & 0.0006 & 0.5052 \\
\hline R24 & $0.3708^{* *}$ & -2.1067 & $0.0081^{* * *}$ & 0.0012 & -0.0048 & $0.0064^{*}$ & 0.2236 \\
\hline R26 & $0.4572^{* *}$ & -0.0753 & 0.0018 & -0.0137 & 0.0186 & $-0.0356^{* * *}$ & 0.4214 \\
\hline R27 & $0.6165^{* * *}$ & -0.4912 & $0.0112^{* *}$ & 0.0043 & 0.0055 & 0.0048 & 0.1953 \\
\hline R28 & $0.6783^{* * *}$ & 4.3248 & $0.0050^{* *}$ & 0.0016 & -0.0050 & \begin{tabular}{|l|}
0.0017 \\
\end{tabular} & 0.4781 \\
\hline R29 & $0.3325^{* *}$ & -7.4647 & 0.0004 & 0.0061 & 0.0005 & 0.0044 & 0.1304 \\
\hline R30 & $0.3540^{* * *}$ & 4.0105 & 0.0043 & 0.0038 & 0.0026 & -0.0016 & 0.1093 \\
\hline R31 & $0.6498^{* * *}$ & $4.9294^{*}$ & $0.0057^{* *}$ & 0.0032 & -0.0046 & 0.0019 & 0.4607 \\
\hline R32 & $0.5832^{* * *}$ & -0.2481 & $0.0092^{* * *}$ & 0.0070 & -0.0008 & 0.0008 & 0.1732 \\
\hline R33 & $0.9379^{* * *}$ & -2.7511 & 0.0031 & 0.0004 & -0.0002 & 0.0015 & 0.4538 \\
\hline R34 & $0.5125^{*}$ & -5.9068 & 0.0057 & 0.0057 & -0.0033 & -0.0129 & 0.2165 \\
\hline R35 & $0.9841^{* * *}$ & -9.2107 & $0.0135^{* *}$ & -0.0020 & 0.0268 & $-0.0189^{* *}$ & 0.4730 \\
\hline
\end{tabular}

Notes: MR: Spanish stock market return, IR: (long-term) interest rate, SMB: size factor, HML: value factor, RMW: profitability factor, CMA: investment factor.

${ }^{*} p<0.10,{ }^{* *} p<0.05,{ }^{* * *} p<0.01$.

Source: Own preparation from Eviews results.

R10 (Bankinter), R17 (Gamesa) and R31 (Banco Santander). In addition, this sensitivity is very high, since in all the cases the coefficients are much larger than the unit is. The only company that presents negative sensitivity is R18 (Gas Natural Fenosa), so that increases in the long-term interest rate mean decreases in its returns.

For the "size" (SMB) explanatory variable, it is statistically significant for twelve companies (almost $43 \%$ of the analysed companies). Specifically, companies that show a positive and statistically significant sensitivity to changes in the 
"size" factor are R2 (Acciona), R3 (Acerinox), R8 (Banco Sabadell), R10 (Bankinter), R16 (Ferrovial), R23 (Indra), R24 (Mapfre), R27 (OHL), R28 (BBVA), R31 (Banco Santander), R32 (Sacyr) and R35 (Técnicas Reunidas). Thus, the larger (smaller) the business size, the higher (lower) is the expected return. In addition, the highest sensitivity is found in OHL and Técnicas Reunidas, and the least sensitivity in BBVA and Banco Santander.

The "value" (HML) explanatory variable is statistically significant and positive for R3 (Acerinox), R15 (FCC), R16 (Ferrovial) and R23 (Indra), and the highest sensitivity corresponds to FCC. So, the higher the business growth, the higher would be the expected return for the companies mentioned.

Regarding the "profitability" (RMV) factor, it is not statistically significant for most companies, and is statistically significant and positive only for R16 (Ferrovial).

And finally, as regards the "investment" (CMA) explanatory variable, about $14 \%$ of the companies show statistically significant sensitivity, such as R21 (Iberdrola), R24 (Mapfre), R26 (Arcelomittal) and R35 (Técnicas Reunidas). This sensitivity is positive for Iberdrola and Mapfre, and negative for Arcelomittal and Técnicas Reunidas.

In this study, the explanatory power of the proposed factor model is quite different between companies. The adjusted coefficient $\mathrm{R}^{2}$ shows mean values around $25 \%$, and it is almost 50\% for R28 (BBVA), R31 (Banco Santander), R33 (Telefónica) and R35 (Técnicas Reunidas) and somewhat higher than $50 \%$ for R23 (Indra).

\subsubsection{Recent financial crisis sub-period: September 2008-April 2016}

This sub-section includes the analysis for the second sub-sample, the recent financial crisis sub-period. During this crisis sub-period, the results of our proposed model using long-term interest rates are shown in Table 5.

First, all companies present a positive and statistically significant sensitivity to changes in the stock market return. In addition, the companies whose coefficients (and sensitivity) are greater than one, which means that they overreact to changes in the market, are R9 (Bankia), R17 (Gamesa), R26 (Arcelomittal), R27 (OHL), R28 (BBVA), R31 (Banco Santander), R32 (Sacyr) and R35 (Técnicas Reunidas). The least sensitive company to changes in the market return is R6 (Amadeus), followed by R10 (Bankinter), R14 (Enagas), R20 (International Consolidated Airlines Group) and R33 (Telefónica).

About $34 \%$ of the companies present statistically significant sensitivity to changes in long-term interest rates. R11 (Caixabank), R12 (Día), R16 (Ferrovial), R22 (Inditex), R26 (Mittal steel company), R27 (OHL), R30 (Repsol), 
Table 5. Estimates for the crisis sub-sample and long-term interest rates

\begin{tabular}{|c|c|c|c|c|c|c|c|}
\hline Companies & MR & $\Delta \mathbf{I N T}$ & SMB & $\Delta$ HML & RMW & $\Delta$ CMA & Adj. $R^{2}$ \\
\hline R1 & $0.5538^{* * *}$ & 1.1233 & $0.0056^{* *}$ & -0.0013 & -0.0054 & 0.0010 & 0.3191 \\
\hline R2 & $0.9377^{* * *}$ & 0.3967 & $0.0168^{* * *}$ & -0.0028 & 0.0013 & 0.0025 & 0.2693 \\
\hline R3 & $0.8616^{* * *}$ & 2.6447 & $0.0101^{* * *}$ & -0.0024 & -0.0036 & -0.0015 & 0.3855 \\
\hline R4 & $0.7509^{* * *}$ & -0.8457 & $0.0095^{* * *}$ & -0.0019 & -0.0006 & -0.0026 & 0.3499 \\
\hline R5 & $0.6805^{*}$ & -2.6380 & 0.0153 & 0.0153 & -0.0141 & 0.0056 & 0.5120 \\
\hline R6 & $0.1926^{*}$ & 1.7980 & 0.0022 & -0.0016 & -0.0038 & 0.0000 & 0.0126 \\
\hline R7 & $0.7392^{* * *}$ & -1.7473 & $0.0123^{* *}$ & $-0.0071^{*}$ & $-0.0150^{*}$ & 0.0020 & 0.2505 \\
\hline R8 & $0.6283^{* * *}$ & $-4.8723^{* *}$ & 0.0039 & -0.0020 & -0.0098 & 0.0022 & 0.3256 \\
\hline R9 & $1.7963^{*}$ & $-20.2970^{*}$ & 0.0179 & 0.0098 & 0.0313 & 0.0143 & -0.0421 \\
\hline R10 & $0.4179^{*}$ & -1.8932 & 0.0059 & $-0.0080^{* *}$ & $-0.0170^{* *}$ & 0.0006 & 0.0989 \\
\hline R11 & $0.8922^{* * *}$ & $3.0069^{*}$ & $0.0066^{*}$ & $-0.0062^{* *}$ & $-0.0126^{* *}$ & -0.0008 & 0.4428 \\
\hline R12 & $0.6183^{* * *}$ & $5.7550^{* * *}$ & 0.0026 & -0.0021 & -0.0090 & -0.0032 & 0.2232 \\
\hline R13 & $0.5977^{* * *}$ & 0.8172 & 0.0071 & $-0.0118^{* * *}$ & -0.0120 & 0.0058 & 0.1478 \\
\hline R14 & $0.4791^{* * *}$ & 0.6716 & 0.0034 & -0.0027 & -0.0020 & -0.0016 & 0.2792 \\
\hline R15 & $0.8481^{* * *}$ & -2.5674 & 0.0084 & $-0.0084^{* *}$ & -0.0025 & $0.0093^{*}$ & 0.2047 \\
\hline R16 & $0.9601^{* * *}$ & $3.5904^{* *}$ & $0.0107^{* * * *}$ & $-0.0052^{* *}$ & 0.0057 & 0.0008 & 0.3838 \\
\hline R17 & $1.3657^{* * *}$ & 3.8221 & $0.0300^{* * *}$ & $-0.0079^{*}$ & -0.0078 & 0.0051 & 0.4215 \\
\hline R18 & $0.7199^{* * *}$ & 2.3958 & 0.0056 & $-0.0119^{* * * *}$ & $-0.0125^{* *}$ & 0.0040 & 0.3429 \\
\hline R19 & $0.6058^{* * *}$ & 1.1924 & $0.0119^{* * *}$ & -0.0030 & 0.0062 & -0.0005 & 0.1497 \\
\hline R20 & $0.5305^{*}$ & 0.4664 & 0.0051 & -0.0049 & -0.0095 & $-0.0088^{*}$ & 0.1288 \\
\hline R21 & $0.6943^{* * *}$ & 1.1737 & $0.0070^{* * *}$ & $-0.0053^{* * *}$ & -0.0057 & -0.0014 & 0.4600 \\
\hline R22 & $0.5720^{* * *}$ & $3.3172^{* * *}$ & $0.0069^{* * *}$ & 0.0021 & 0.0057 & -0.0005 & 0.3113 \\
\hline R23 & $0.5538^{* * *}$ & -0.2806 & $0.0102^{* * *}$ & -0.0031 & -0.0014 & 0.0014 & 0.1857 \\
\hline R24 & $0.8376^{* * *}$ & 1.7086 & $0.0083^{* *}$ & $-0.0091^{* * * *}$ & $-0.0133^{* *}$ & 0.0049 & 0.4196 \\
\hline R25 & $0.5473^{*}$ & -0.5914 & 0.0041 & 0.0035 & 0.0006 & 0.0014 & -0.0215 \\
\hline R26 & $1.4702^{* * *}$ & $10.8020^{* * *}$ & $0.0250^{* * *}$ & -0.0052 & -0.0064 & -0.0011 & 0.5195 \\
\hline R27 & $1.3318^{* * *}$ & $6.4485^{* *}$ & $0.0178^{* * *}$ & $-0.0121^{* * * *}$ & -0.0137 & 0.0047 & 0.4128 \\
\hline R28 & $1.0891^{* * *}$ & 1.3344 & $0.0064^{*}$ & $-0.0070^{* * *}$ & $-0.0121^{* *}$ & 0.0031 & 0.5707 \\
\hline R29 & $0.5917^{* * *}$ & 1.4666 & $0.0058^{* *}$ & $-0.0033^{*}$ & -0.0003 & -0.0017 & 0.3354 \\
\hline R30 & $0.9007^{* * *}$ & $3.1450^{*}$ & 0.0048 & $-0.0051^{* *}$ & \begin{tabular}{|c|}
-0.0059 \\
\end{tabular} & -0.0015 & 0.4463 \\
\hline R31 & $1.1791^{* * *}$ & $2.9335^{*}$ & $0.0093^{* * *}$ & $-0.0059^{* *}$ & -0.0071 & 0.0042 & 0.5744 \\
\hline R32 & $1.8504^{* * *}$ & 4.7237 & $0.0180^{* * *}$ & $-0.0141^{* * *}$ & \begin{tabular}{|l|}
-0.0081 \\
\end{tabular} & -0.0021 & 0.5101 \\
\hline R33 & $0.5219^{* * *}$ & -0.1121 & 0.0002 & -0.0015 & -0.0045 & -0.0042 & 0.3420 \\
\hline R34 & $0.9215^{* * *}$ & $4.1983^{*}$ & $0.0095^{* *}$ & -0.0032 & $-0.0145^{* *}$ & -0.0016 & 0.3765 \\
\hline R35 & $1.0055^{* * *}$ & $7.5965^{* * *}$ & $0.0177^{* * *}$ & -0.0006 & 0.0014 & -0.0004 & 0.4601 \\
\hline
\end{tabular}

Notes: MR: Spanish stock market return, IR: (long-term) interest rate, SMB: size factor, HML: value factor, RMW: profitability factor, CMA: investment factor.

${ }^{*} p<0.10,{ }^{* *} p<0.05,{ }^{* * *} p<0.01$.

Source: Own preparation from Eviews results. 
R31 (Banco Santander), R34 (Mediaset) and R35 (Técnicas Reunidas) show a positive sensitivity, and in addition, Mittal steel company and Técnicas Reunidas overreact to changes in interest rates. According to Díaz and Jareño (2013), this positive effect could be explained because an increase in interest rates is considered as "good news" for investors in the context of crisis. In contrary, R8 (Banco Sabadell) and R9 (Bankia) have statistically significant and negative sensitivity to changes in this explanatory factor. So, long-term interest rates exhibit high explanatory power.

The "size" factor (SMB) is statistically significant for all companies, except for R5 (Aena), R6 (Amadeus), R8 (Banco Sabadell), R9 (Bankia), R10 (Bankinter), R12 (Día), R13 (Endesa), R14 (Enagas), R15 (FCC), R18 (Gas Natural Fenosa), R20 (IAG), R25 (Merlin Properties), R30 (Repsol) and R33 (Telefónica). The rest of the companies (about $60 \%$ of them) show positive sensitivity to changes in SMB. In addition, this sensitivity is higher for R17 (Gamesa), R26 (Arcelomittal), R27 (OHL), R32 (Sacyr) and R35 (Técnicas Reunidas), and lower for R1 (Abertis) and R29 (REE). Therefore, the SMB factor also shows high explanatory power.

The "value" factor (HML) influences significantly and negatively on $46 \%$ of the companies, specifically, R7 (Banco Popular), R10 (Bankinter), R11 (Caixabank), R13 (Endesa), R15 (FCC), R16 (Ferrovial), R17 (Gamesa), R18 (Gas Natural Fenosa), R21 (Iberdrola), R24 (Mapfre), R27 (OHL), R28 (BBVA), R29 (Red Eléctrica), R30 (Repsol), R31 (Banco Santander) and R32 (Sacyr). Among them, the highest sensitivity to changes in this factor corresponds to Red Eléctrica and the lowest to Sacyr.

For the "profitability" factor (RMW), the sensitivity is statistically significant and negative in about $20 \%$ of the companies, such as R7 (Banco Popular), R10 (Bankinter), R11 (Caixabank), R18 (Gas Natural Fenosa), R24 (Mapfre), R28 (BBVA) and R34 (Mediaset).

Finally, regarding the "investment" variable (CMA), it is only statistically significant and positive for R15 (FCC) and negative for R20 (IAG). Thus, the explanatory power of CMA is quite low.

As previously said, the explanatory power is quite different between companies. The mean adjusted $\mathrm{R}^{2}$ is about $32 \%$. Besides, the explanatory power exceeds $50 \%$ for R5 (Aena), R26 (Arcelomittal) and R32 (Sacyr) and almost reaches 60\% for R28 (BBVA) and R31 (Banco Santander). Therefore, the explanatory power of the augmented Fama and French (2015) five-factor model increases in this recent financial crisis sub-period in comparison with the pre-crisis sub-period. 


\subsection{Short-term interest rate analysis}

Additionally, to check the robustness of these results, the sensitivity of stock business returns to changes in short-term interest rates (proxied by 3-month treasury bill rates) has been tested in the extended Fama and French specification. Thus, the extended FF5 model that includes short-term interest rates is represented as follows:

$$
R_{j t}=\alpha_{j}+\beta_{j} \cdot M R_{t}+\mu_{j} \cdot \Delta R F_{t}+\gamma_{t} \cdot S M B_{t}+\tau_{t} \cdot \Delta H M L_{t}+\varphi_{t} \cdot R M V_{t}+\delta_{t} \cdot \Delta C M A_{t}+\varepsilon_{j t}
$$

where, $\Delta R F_{t}$ is the non-expected change in the short-term (risk-free) nominal interest rate.

The results of this robustness exercise show that the sensitivity of Spanish companies to movements in the selected risk factors, using 3-month treasury bill rates, is in line with the results using fluctuations in 10-year government bond yields for all companies regardless of the sub-period examined. ${ }^{13}$ This evidence is fully in line with some previous studies such as Ferrando et al. (2017), among others. Furthermore, these results confirm the reliability of previous results from the augmented FF5 model proposed in this research.

Table 6 summarizes the percentages of companies that show statistically significant sensitivities to variations in the explanatory variables in the full period as well as in the two sub-periods (pre-crisis and crisis) both in short- and long-term interest rates. In actual fact the percentage of companies with statistically significant sensitivity to the "size", "value", "profitability" and "investment" factors is slightly lower in the short-term interest rate analysis in comparison with the longterm interest rates analysis.

Table 6. Percentages of statistically significant sensitivities (short- and long-term interest rates), $\%$

\begin{tabular}{l|l|r|r|r|r|r|r}
\hline Period & Models/Variables & \multicolumn{1}{|c|}{ MR } & \multicolumn{1}{|c|}{ INT } & \multicolumn{1}{|c|}{ SMB } & $\Delta$ HML & RMW & $\Delta$ CMA \\
\hline \multirow{3}{*}{ Full period } & Long-term interest rates & 97.14 & 28.57 & 71.43 & 17.14 & 25.71 & 37.14 \\
\cline { 2 - 8 } & Short-term interest rates & 97.14 & 11.43 & 51.43 & 11.43 & 22.86 & 31.43 \\
\cline { 2 - 8 } & Difference & 0.00 & 17.14 & 20.00 & 5.71 & 2.85 & 5.71 \\
\hline \multirow{2}{*}{$\begin{array}{l}\text { Pre-crisis } \\
\text { sub-period }\end{array}$} & Long-term interest rates & 92.86 & 21.43 & 42.86 & 14.29 & 3.57 & 14.29 \\
\cline { 2 - 8 } & Short-term interest rates & 89.29 & 3.57 & 46.43 & 14.29 & 10.71 & 7.14 \\
\cline { 2 - 8 } & Difference & 3.57 & 17.86 & -3.57 & 0.00 & -7.14 & 7.15 \\
\hline \multirow{2}{*}{$\begin{array}{l}\text { Crisis } \\
\text { sub-period }\end{array}$} & Long-term interest rates & 100 & 34.29 & 60.00 & 45.71 & 20.00 & 5.71 \\
\cline { 2 - 8 } & Short-term interest rates & 97.14 & 20.00 & 65.71 & 51.43 & 22.86 & 2.86 \\
\cline { 2 - 8 } & Difference & 2.86 & 14.29 & -5.71 & -5.72 & -2.86 & 2.85 \\
\hline
\end{tabular}

13 These results for the whole sample period and by sub-periods (using short-term interest rates) are available upon request. 
Nevertheless, the number of companies sensitive to changes in short-term interest rates is reduced by more than half. Thus, this result corroborates our choice of long- instead of short-term interest rates as explanatory variable.

\section{CONCLUDING REMARKS}

This paper analyses the sensitivity of company returns in the Spanish stock market to changes in a set of explanatory factors, such as the stock market return, long-term (and short-term) interest rates, and other risk factors proposed by Fama and French, which are: the "size" factor, the "value" factor, the "profitability" factor, and the "investment" factor.

Thus, the main objective of the present study is to determine the effect of each explanatory factor on the returns of the companies listed in the Spanish index IBEX-35 in the period from January 2000 to April 2016. In addition, to check the robustness of the results in the framework of the augmented Fama and French five-factor model, two robustness tests have been carried out. The first one estimates this model by splitting the whole sample period into sub-periods (pre-crisis and recent financial crisis). This robustness test may enable us to know which stock business returns are most sensitive to changes in the risk factors included in this study, considering the relevant economic and historical events, such as the fall of Lehman Brothers in September 2008 (Ferrando et al. 2017). To reach greater consistency in our conclusions, the second robustness test estimates the extended FF5 model using an alternative risk factor for the nominal interest rate: the short-term (instead of long-term) interest rate. As defended by previous literature, this robustness test corroborates the main results obtained in this research and our choice of long- instead of short-term interest rates as an explanatory variable.

The Spanish stock market return shows a positive and statistically significant effect on the companies' returns. The results obtained in the case of the interest rate as an explanatory variable show a negative and statistically significant sensitivity of the company returns to changes in this variable. Nevertheless, shortterm interest rates seem to have a negative effect, meanwhile long-term interest rates would show a positive impact on some company returns (considering future expectations). Moreover, the effect of long-term interest rates on stock business returns would be greater than the impact of short-term interest rates, at least in terms of number of companies with statistically significant sensitivities to changes in interest rates.

Among the risk factors proposed by Fama and French, the "size" and the "value" factors show a high level of statistical significance in the whole sample 
period and in the recent financial crisis sub-period. The "size" factor reveals a positive impact on stock business returns while the "value" factor produces a negative impact. In addition, the "profitability" and the "investment" factors also show a relevant level of statistical significance, mainly in the whole sample, with negative sign for "profitability" and positive sign for "investment". Although "profitability" and "investment" factors seem to be more relevant for the full period, the "profitability" factor also keeps its relevance in the crisis sub-period.

As far as the analysis at the sector level is concerned, it is remarkable that all but one of the 35 companies listed in the Spanish index (IBEX-35) are mainly affected by the variations in market returns. Moreover, sector 1 (Oil and Energy) shows one of the greatest percentages of companies sensitive to changes in the "size" and the "investment" factors, and sector 2 (Basic Materials, Industry and Construction) presents one of the highest percentages of companies sensitive to variations in the long-term interest rates as well as in the "size" factor. Companies of sector 5 (Financial and Real Estate Services) are highly sensitive to changes in the other risk factors proposed by Fama and French. Additionally, sectors 2 and 5 show the highest explanatory power. Thus, Fama and French five-factor model may be more suitable to forecast portfolio returns than their three-factor model.

\section{REFERENCES}

Akhtaruzzaman, M. - Shamsuddin, A. - Easton, S. (2014): Dynamic Correlation Analysis of Spillover Effects of Interest Rate Risk and Return on Australian and US Financial Firms. Journal of International Financial Markets, Institutions and Money, 31(1): 378-396.

Angelidis, T. - Tessaromatis, N. (2017): Global Equity Country Allocation: An Application of Factor Investing. Financial Analysts Journal, 73(4): 55-73.

Bartram, S. (2002): The Interest Rate Exposure of Nonfinancial Corporations. European Finance Review, 6(1): 101-125.

Chiah, M. - Chai, D. - Zhong, A. - Li, S. (2016): A Better Model? An Empirical Investigation of the Fama-French Five-factor Model in Australia. International Review of Finance, 16(4): 595-638.

Díaz, A. - Jareño, F. (2013): Inflation News and Stock Returns: Market Direction and Flow-Through Ability. Empirical Economics, 44(22): 775-798.

Fama, E. F. - French, K. R. (1993): Common Risk Factors in the Returns on Stocks and Bonds. Journal of Financial Economics, (33): 3-56.

Fama, E. F. - French, K. (2015): A Five-Factor Asset Pricing Model. Journal of Financial Economics, 116(3): 1-22.

Fama, E. F. - French, K. (2017): International Tests of a Five-Factor Asset Pricing Model. Journal of Financial Economics, 123 (3): 1-23.

Ferrando, L. - Ferrer, R. - Jareño, F. (2017): Interest Rate Sensitivity of Spanish Industries: A Quantile Regression Approach. The Manchester School, 85(2): 212-242.

Ferrer, R. - Gonzalez, C. - Soto, G. M. (2010): Linear and Nonlinear Interest Rate Exposure in Spain. Managerial Finance, 36(5): 431-451. 
Guoa, B. - Zhangb, W. - Zhangb, Y. - Zhange, H. (2017): The Five-Factor Asset Pricing Model Tests for the Chinese Stock Market. Pacific-Basin Finance Journal, 43: 84-106.

Harshita - Singh, S. - Yadav, S. S. (2015): Indian Stock Market and the Asset Pricing Models. Procedia Economics and Finance, 30: 294-304.

He, Z. L. - Zhu, J. - Zhu, X. (2015): Dynamic Factors and Asset Pricing: International and Further US Evidence. Pacific-Basin Finance Journal, 32: 21-39.

Huynh, T. D. (2017): Conditional Asset Pricing in International Equity Markets. International Review of Economics and Finance, 49: 168-189.

Jareño, F. (2008): Spanish Stock Market Sensitivity to Real Interest and Inflation Rates: An Extension of the Stone Two-Factor Model with Factors of Fama and French Three-Factor Model. Applied Economics, 40(24): 3159-3171.

Jareño, F. - Navarro, E. (2010): Stock Interest Rate Risk and Inflation Shocks. European Journal of Operational Research, (201): 337-348.

Jareño, F. - Ferrer, R. - Miroslavova, S. (2016): US Stock Market Sensitivity to Interest and Inflation Rates: A Quantile Regression Approach. Applied Economics, 48(26): 2469-2481.

Jianzhou, Z. - Morsheda, H. - Wanli, L. (2007): Bank Size and Interest-Rate Sensitivity of Bank Stock Returns. International Journal of Business, Accounting, and Finance, 1(1): 1-25.

Sevillano, M. C. - Jareño, F. (2018): The Impact of International Factors on Spanish Company Returns: A Quantile Regression Approach. Risk Management, 20(1): 51-76.

Stone, B. K. (1974): Systematic Interest-Rate Risk in a Two-Index Model of Returns. Journal of Financial and Quantitative Analysis, 9(5): 709-721.

Yang, Q. - Li, L. - Zhu, Q. - Mizrach, B. (2017): Analysis of US Sector of Services with a New Fama-French 5-Factor Model. Applied Mathematics, 8: 1307-1319. 